\title{
Gênero e religião: uma análise de caso na Paróquia São José, Bicas - MG
}

\author{
Gender and religion: a case study in São José Parish, Bicas - MG
}

Ana Luíza Gouvêa Neto ${ }^{1}$

\begin{abstract}
RESUMO: O presente texto tem como objetivo refletir acerca do lugar feminino no interior do espaço religioso, sobretudo, da igreja católica São José, situada na cidade mineira de Bicas. Pensar a mulher no espaço religioso requer pensar na construção da identidade sexuada e no papel desempenhado pela igreja na construção da identidade feminina. Pensar que as problematizações referentes a uma perspectiva estruturalista de gênero pautada na diferenciação biológica-sexual são questões prováveis em mulheres com escolaridade, seria inocência. O texto traz a fala de uma serva do grupo de oração que reforça a normatização imposta pela igreja ao longo da história de longa duração.
\end{abstract}

PALAVRAS-CHAVE: Gênero; Religião; Bicas.

ABSTRACT: The main purpose of this text is the place of the feminine within the religious space, above all, of the Catholic church of São José, located in the mining town of Bicas. To think of a woman without space requires thinking of the construction of sexual and paperless identity in the church in the construction of the feminine word. Thinking that the problematizations are a structuralist perspective of gender in the question of socioenvironmental differentiation in women with schooling, it would be innocence. The text speaks of a series of groups that reinforce the normalization of the church throughout the history of the long duration.

KEYWORDS: Gender; Religion; Bicas.

\section{Introdução}

Objetiva-se abordar a articulação existente entre gênero e religião dentro de uma das pastorais da Paróquia São José, pertencente ao Município de Bicas, Minas Gerais. Situada na Zona da Mata Mineira, a Paróquia São José de Bicas foi criada em 21 de novembro de 1921, por Dom Silvério Gomes Pimenta ${ }^{2}$, Arcebispo de Mariana. Inicialmente, essa pertencia ao

\footnotetext{
${ }^{1}$ Doutora em Ciência da Religião pelo Departamento de Pós-graduação em Ciência da Religião, da Universidade Federal de Juiz de Fora. E-mail: analu172@hotmail.com

${ }^{2}$ Dom Silvério Gomes Pimenta foi professor, orador sacro, biógrafo, prelado, e arcebispo de Mariana. Foi o primeiro prelado brasileiro com cadeira entre os consagrados escritores da Academia Brasileira de Letras.
} 
Distrito São José de Bicas, integrado ao Município de Guarará ${ }^{3}$, nesse período ainda como Comarca de Mar de Espanha. Desde os seus primórdios a capela já abrigava a imagem de São José padroeiro da cidade e ao longo dos anos sofreu várias reformas e restaurações, recebendo na década de 1940 seus vitrais, que a tornaram famosa e considerada uma das mais belas Igrejas da região, por muitos católicos e mesmo fiéis de outras religiões.

A Paróquia São José é composta por diversas Pastorais e tendo como referência o depoimento fornecido por uma das servas, participante de um dos núcleos, de uma das Pastorais, pretende-se abordar como a participação da mulher, sobretudo jovem, se dá dentro da Igreja e as consequências geradas por esta participação em seu cotidiano. Trata-se, portanto, de interpretar a representação do papel do feminino dentro da igreja e a influência desta representação no dia a dia da mulher, buscando descobrir tensões e passagens entre seu papel e a hierarquia dominante masculina. Os dados para a pesquisa foram agrupados através de entrevistas com integrante do núcleo do grupo de oração, levantamento e debruçamento minucioso sobre fontes documentais e bibliográficas, o que possibilitou uma análise inicial para depois uma interpretação do fenômeno estudado a posteriori ${ }^{4}$ aos moldes weberianos (Weber, 1989).

O estudo de caso presente neste artigo exemplifica a mudança no quadro religioso brasileiro. O mesmo começa a tomar novas formas, no que concerne ao aumento dos estudos nas academias, modificando a abordagem do assunto, antes pouco abordado como cientifico nos anos de 1970. Quando a partir de então o estudo da religião assume uma nova perspectiva. Cândido Procópio Ferreira Camargo (1973) com seu livro "Católicos, Protestantes, Espíritas" se torna pioneiro para a perspectiva de mudança. No entanto, a teoria de gênero articulada à religião é relativamente nova, e quando estudada e analisada, ainda se prende a uma visão patriarcal e masculina (Rocha, 2008).

Nasceu em Congonhas do Campo - MG, em 12 de janeiro de 1840, falecendo em Mariana - MG, em 30 de agosto de 1922

${ }^{3}$ A cidade de Bicas teve sua emancipação em 1923 deixando, assim de integrar o Município de Guarará como Distrito, a mesma foi elevada a categoria de Município em 10 de setembro de 1925, pela Lei Estadual n 893. No entanto, a Comarca só foi criada e instalada e 29 de junho de 1935, das quais fazem partes hoje as cidades de Bicas, Guarará, Maripá de Minas e Pequeri.

4 "Tal conceito histórico deve ser gradualmente estruturado a partir das partes individuais tomadas à realidade histórica que o institui. Assim, o conceito final e definitivo, não pode figurar no inicio da investigação.”(WEBER, 1989). 
Consequentemente, a bibliografia abarcada será baseada na literatura que vem sendo desenvolvida desde o fim dos anos $1970^{5}$ acerca de gênero dentro da religião. Pode-se identificar duas linhas interpretativas no que concerne ao estudo interseccional de gênero e religião, com diferentes expressividades no que tange a adeptos e estudiosos. A menos expressiva defensora de que o ideário mágico e emocionalista dentro do pentecostalismo, CEB'S e RCC servem como base para a manutenção e reforço da submissão feminina; e a segunda vertente, mais expressiva, na qual, há uma relativização da categoria mulher dentro de culturas e classes sociais distintas, que busca analisar o papel da religião dentro da vida das mulheres e as consequências trazidas para suas vidas sociais, buscando ressaltar os benefícios, ainda que de pequeno alcance, na diminuição da opressão feminina (Couto, 2001). O estudo de vertentes distintas sobre o papel desempenhado pela mulher dentro da religião servirá para a análise imparcial e produção de um resultado neutro, o qual, não corra o risco de pareceres e conclusões precipitadas ou superficiais baseadas em valores marcados por uma possível crença.

Segundo a serva entrevistada do grupo de oração, a vida comunitária em Bicas, tem uma forte influência da religião católica no seu cotidiano, e esta pode ser constatada mais nitidamente em momentos de efervescência coletiva ${ }^{6}$, tais como: feriados santos, nos quais fica mais fácil perceber a abrangência da religião católica dentro da cidade e seu papel de regulação social. Ainda que a modernidade religiosa venha acompanhada com uma pluralidade de ideias e práticas, o enfraquecimento das religiões como reguladoras sociais ainda não se deu por completo. Hervieu-Léger (1947), demonstra como a religião vem perdendo sua força em sua teoria da "secularização", a qual, a autora se baseia em três elementos, que são: a racionalização, a cisão com a tradição e a diferenciação das instituições. Contudo, a religião ainda exerce uma influencia social, a partir de uma construção sociocultural, exercendo trocas simbólicas de poder, capazes de desenhar e redesenhar as sociedades, o que é visto por Bourdieu (1989) como trocas estruturantes, quer dizer, estruturadas e estruturadoras.

\footnotetext{
${ }^{5}$ Souza (2004) demonstra que no que diz respeito ao apelo cientifico no Brasil a religião ainda se encontra pouco discutida, e muito menos admitida. Consequentemente as pesquisas e estudos se encontram de formas escassas e muito pouco publicas. Vemos um maior alargamento do estudo e publicações em revistas feministas como, Cadernos Pagu e Mandrágora. Desta forma pode-se identificar que no Brasil o objeto de estudo de religião vem ocupando ao longo dos anos " um lugar marginal e de importância secundária nas academias".

${ }^{6}$ Para Durkheim, as crenças coletivas presentes em sociedades primitivas, ou contemporâneas, independente de quaisquer conteúdos que possam ter são responsáveis pela continuidade das sociedades, produzindo ritos de efervescência coletivas, capazes de coesionar e reavivar estas sociedades em torno do sagrado.
} 
Nota-se em Geertz (1978), que a cultura deve ser analisada como um sistema simbólico, o qual, através de analise e interpretação se busca uma explicação presente em qualquer objeto. Deste modo a religião deve ser considerada como um sistema simbólico o qual se faz necessária à análise dos símbolos para o alcance de significados, através de um enfoque cultural, quer dizer, esta deve ser considerada como uma cultura religiosa. Não obstante, a relação entre gênero e religião também deve assumir um enfoque cultural, na qual, representações, signos e símbolos devam ser interpretados para a obtenção de interpretações e explicações. No entanto, a relação entre gênero e religião, ainda, muitas vezes, encontra-se baseada em uma distinção biológico-social (Rocha, 2008).

Neste contexto, sexo e gênero não são utilizados como sinônimos, ao contrário, enquanto sexo vem de uma diferenciação biológica macho/fêmea, a distinção entre gênero se constrói a partir de um universo cultural e social (Jurkewicz,1996), no qual, o individuo é exposto desde o seu nascimento. Portanto, culturalmente, o gênero construído para determinado indivíduo se baseia no sexo do mesmo, quer dizer, no fator biológico de ser macho ou fêmea, conseguintemente, a divisão do trabalho se constrói por meio desta identidade biológico-social. Desse modo, o papel desempenhado pelos gêneros dentro do sagrado se dá de forma desigual, consequentemente, podemos concluir que o sagrado é experimentado de formas diferentes por homens e mulheres. Assim sendo, podemos dizer que há um consenso em relação ao papel desempenhado pela mulher dentro das instituições religiosas, nas quais está subordinada a uma posição secundária na hierarquia, comparada aos homens. Para autoras como Rocha (2008), a mulher, se encaixaria na esfera do privado, isto é: dona de casa, mãe de família, reprodutora; enquanto o homem se encaixaria na esfera do público: da rua, do trabalho, da política. Verifica-se, portanto, uma hierarquia, muitas vezes, nem percebida pelas próprias mulheres, na qual, o homem, como dominante, é responsável pelo provento do material e do financeiro, enquanto a mulher, submissa, se incumbe das responsabilidades do lar: arrumar a casa, cuidar das crianças, de forma geral, do trabalho doméstico

A diferenciação por meio biológico-social, se faz presente em diversas instâncias da sociedade, até mesmo dentro da instituição religiosa. Embora, de maneira mais sutil, a religião, junto a outras instituições, exerce influencia no modo em que os sexos se reconhecem socialmente. E é justamente este o problema, apesar de ainda influente e reguladora, a articulação entre religião e gênero ainda se encontra de forma crua deixando 
dúvidas sobre a função de produção e reprodução dos sistemas simbólicos nas relações sociais envolvendo a construção da identidade de gênero e sua hierarquização. A religião como instituição, acaba proporcionando uma ordem simbólica capaz de contribuir para legitimação de uma ordem política.

Dessa forma, como podemos explicar que nas instituições religiosas o maior número de fiéis seja do sexo feminino, uma vez que as mulheres não ocupam cargos hierarquicamente superiores?

A pergunta acima essencializa o problema abordado no presente artigo: a diferenciação e hierarquização dos gêneros no interior do espaço religioso, nesse caso, na paróquia São José em Bicas - MG. Pretende ainda, refletir se essa diferenciação é capaz de gerar experiências desiguais entre homens e mulheres com o sagrado.

\section{Problemas de gênero e a dominação masculina}

No entanto, para a percepção da diferenciação de gênero e possíveis desigualdades geradas é necessário entender como se fundamentam os conceitos e categorias de gêneros, bem como, as estruturas responsáveis por suas construções e reproduções. Butler (2012) demonstra a necessidade de problematização da categoria de gênero para o entendimento da ordem social estabelecida e perpetuada através dos tempos. De acordo com a autora, a discussão deve se iniciar no poder, que segundo ela, assume uma função dual (Butler, 2012). Quer dizer, ao mesmo tempo em que o poder é jurídico, é também produtor. O poder, desta forma, atua na esfera da legitimação política, regulamentando, criando, e perpetuando identidades, como também, é este poder, o responsável pela produção da identidade, ao passo que ao mesmo tempo em que ele representa, ele próprio cria a identidade a qual representa, por forma de exclusão. A noção de gênero é inserida neste contexto, não podendo ser separada das relações políticas e culturais nas quais é construída e mantida representando consequentemente uma identidade. Salvo problematizações e especulações, a noção de gênero vem embutida em algo culturalmente construído, isto posto, o corpo sexuado, ganha signos e símbolos culturais.

Em Bourdieu (2011) podemos perceber que toda ordem estabelecida é construída e mantida através de símbolos, e são estes símbolos os responsáveis pela perpetuação da estrutura hierárquica binária de poder na qual os gêneros estão inseridos. Conseguintemente, 
notam-se as categorias de gênero sustentando a própria hierarquia de gênero e a heterossexualidade compulsória - processo de socialização a qual, "garante" que os opostos se atraiam - logo, perpetuando a dominação masculina. Esta manutenção da ordem social naturalizada capaz de transformar gênero em habitus sexuados, deve-se a uma visão falocêntrica e uma cosmologia androcêntrica de mundo. É graças a este esquema de representação, de cunho universal, que os princípios desiguais e hierárquicos entre os gêneros se naturalizam. Assim, Bourdieu (2011) chega à conclusão que a diferença biológica entre os sexos se baseia a partir da diferença anatômica entre os órgãos sexuais, garantindo a legitimação da diferença natural entre os gêneros e da divisão do trabalho. Tem-se, portanto, um círculo vicioso: a visão social é responsável pela construção de diferenças anatômicas, enquanto esta diferença socialmente construída se torna base para a naturalização da visão social a qual se alicerça.

Resultado: a estrutura binária de gênero tem como base fundante a hierarquia entre os habitus sexuados construídos através de uma visão androcêntrica de mundo, naturalizando a divisão social do trabalho, os comportamentos e a dominação masculina. Assim sendo, o gênero masculino pode ser identificado como marcador para a construção, não somente da identidade masculina, mas, sobretudo, da identidade feminina. Em outras palavras, a mulher se torna o negativo do homem, ela é o "Outro" feminino, este fora das normas universalizantes, confirmando a cosmovisão androcêntrica de mundo. É esta visão que naturaliza a heterossexualidade compulsória, mostrando os objetivos reprodutivos deste sistema através dos gêneros inteligíveis e/ou dos gêneros relacionais. O que se tem por consequência é a manutenção das relações de continuidade e coerência entre sexo, gênero, desejo e prática sexual, perpetuando a hierarquização binária através de uma matriz cultural responsável pela construção e manutenção da ordem simbólica social.

No entanto, de quais formas e através de quais estruturas este esquema social é perpetuado e mantido?

A ordem social dominante masculina não deve ser considerada como a-histórica, pelo contrário, são produtos de trabalhos de reprodução de um sentido simbólico por agentes específicos, tais como: Família, Igreja, Estado e Escola. Dessa maneira, a perpetuação deste sistema de visão dominante deve-se a estruturas que vão sendo incorporadas nas coisas e corpos ao longo dos tempos. Tanto Butler, quanto Bourdieu, concordam que pode haver uma ruptura neste sistema através do ato, uma vez que este é um produto histórico, cabendo aos 
dominados assumirem posturas de fora da visão dominante, uma vez que, estando inseridos neste sistema, tanto dominantes quanto dominados estão a mercê desta visão dominadora. No entanto, a ordem masculina se vê reproduzida constantemente ao longo dos tempos, com agentes e instituições concorrendo para garantir esta permanência.

\section{O grupo Mártir São Sebastião e sua dinâmica}

Situada na Zona da Mata Mineira, a cidade de Bicas tem sua economia fortemente marcada pela oferta de serviços, a qual ocupa $80 \%$ do PIB (Produto Interno Bruto) seguida pela indústria com $15 \%$ e a agropecuária com pouco mais de $3,5 \%$. O campo religioso biquense é composto por uma diversificação, no que tange a diferentes religiões, o quadro abaixo apresenta esta diversificação de forma sintetizada.

\begin{tabular}{|c|c|}
\hline \multicolumn{2}{|c|}{$\begin{array}{c}\text { Censo Demográfico - Cidade de Bicas - 2010 } \\
\text { (IBGE, 2010) }\end{array}$} \\
\hline Religião & Número de habitantes \\
\hline Católica apostólica romana & 9613 \\
\hline Evangélicas & 2210 \\
\hline Religião espírita & 762 \\
\hline Umbanda e candomblé & 47 \\
\hline Sem religião & 938 \\
\hline Outras & 83 \\
\hline Total & $\mathbf{1 3 6 5 3}$ \\
\hline
\end{tabular}

Percebe-se que apesar da diversificação no campo religioso, a cidade de Bicas tem $70,4 \%$ de seus habitantes pertencentes à Igreja Católica. Este domínio católico presente na cidade é capaz de marcar uma forte influencia na relação simbólica de seus habitantes entre religião e cotidiano os tornando ativos social e politicamente. No que diz respeito à participação entre homens e mulheres dentro da religião católica a diferença entre os sexos é quase imperceptível, sendo 4921 mulheres para 4692 homens, no total de 9613 adeptos. A Igreja Matriz, Paróquia São José, é responsável por uma forte mobilização da população em prol da comunidade, realizando campanhas, trabalhos pastorais e ações sociais.

A paróquia São José é composta por vinte e sete Pastorais dentro da comunidade demonstrando a forte influência na organização social que esta Igreja ainda exerce nos tempos 
atuais. Dentro de uma modernidade pluralizada, diversificada e cada vez menos regulada pela religião, a cidade de Bicas, parece ainda manter fortes valores religiosos influenciando a vida de seus cidadãos, valores estes que podem ou não, legitimar a desigualdade vivenciada por homens e mulheres. Por este motivo, o grupo de oração Mártir São Sebastião, de moldes carismáticos foi escolhido para demonstrar se existe ou não desigualdades vivenciadas entre homens e mulheres, sobretudo jovens, dentro da religião. Neste contexto serão utilizadas entrevistas feitas com uma das servas integrantes do núcleo de oração, a qual, por motivos de privacidade terá sua identidade preservada e chamada como Vera.

O grupo Mártir São Sebastião tem como padroeira Nossa Senhora das Graças e recebeu este nome por acontecer, inicialmente, na Igreja São Sebastião, situada na cidade de Bicas. Com o passar dos anos foi realocado para Igreja Matriz, a Paróquia São José, por motivos de espaço, uma vez que, o grupo vinha crescendo e a antiga Igreja não comportava todos os participantes. Este, já vem acontecendo há mais de vinte e quatro anos e segue uma tendência carismática ${ }^{7}$, o único deste tipo na cidade, no qual, é valorizada a experiência individual de cada fiel, "propiciando ao frequentador um momento de oração e espiritualidade mais intenso dentro da religião católica." 8

Segundo Vera, esta espiritualidade tocante, fornecida pelo grupo de oração, nem sempre é vivenciada dentro da missa, aos moldes institucionais. Percebe-se no grupo uma entrega espiritual intensa que leva as pessoas a se sentirem livres - os fiéis cantam, louvam, se abraçam - saindo de lá com fé e esperanças renovadas. Neste sentido, os fiéis reconhecem o grupo como um lugar de fé, apoio espiritual e psicológico. $\quad \mathrm{O}$ grupo, diferente da missa, cerimonial e institucional, fornece ao frequentador possibilidades de introspecção e análises de comportamentos através de orações compartilhadas, fornecendo ao frequentador não somente a oração, mas também um momento de reflexão.

As reuniões do grupo ocorrem em dois momentos distintos, no primeiro momento só participa o núcleo do grupo, composto por dezenove integrantes, dos quais, apenas quatro são

\footnotetext{
${ }^{7}$ Para Steil (1998) "Rege os grupo carismáticos o principio de que cada membro é visto como agraciado por um dom espiritual, ou um carisma, que contribui para a vida coletiva de comunidade como um "corpo" ou um "povo". Assim, cada comunidade tem um dom ou carisma particular. Juntas elas formariam uma "comunidade de comunidades" um povo divinamente constituído. É esse principio é que permite que muitas pessoas se envolvam ativamente com os "grupos de oração" da Renovação Carismática Católica e se reúnam semanalmente para orar em forma coletiva." Somado a isto, há na RCC (Renovação Carismática Católica), um novo sentido de leitura da Bíblia enfatizando a experiência mística e o acesso direto ao sagrado, enfatizando, sobretudo o Batismo no Espírito Santo. A RCC, como também, outros movimentos do catolicismo contemporâneo, expressam segundo Mariz (2006) as divergências internas da própria Instituição católica.

${ }^{8}$ Vera, 25 anos, solteira, entrevista realizada em 11 maio 2013.
} 
homens, sendo os demais integrantes mulheres, e apenas dois jovens. Este momento ocorre às quartas feiras das $19 \mathrm{~h} 00$ às $21 \mathrm{~h} 00$ horas, semanalmente, em um espaço cedido pela Igreja de Santa Luzia: o salão de festas. Pois na Igreja Matriz, acontecem encontros de catequese quase que diariamente, não sobrando espaço para as reuniões de núcleo do grupo. Quando o mesmo se encontra ocupado a reunião é transferida para a casa de uma das servas, uma senhora já viúva. Nestes encontros de núcleo são organizadas as tarefas do grupo, orações também ocorrem nestes encontros. O segundo momento é denominado como "Grupão" por Vera, e ocorre na Igreja Matriz todas as terças feiras a partir das 19 h00 horas, consequentemente, este é aberto para o público. Durante estes encontros chegam a comparecer em média noventa participantes, e em sua maioria mulheres.

Esta constatação, acima, suscita inquietações acerca da participação das mulheres na religião e suas funções dentro destas. Bourdieu (2011) ao afirmar que a ordem simbólica é histórica, construída e produzida por agentes e instituições, responsáveis pela perpetuação desta hierarquia binária entre os sexos, trata a Igreja, especialmente a católica, como um dos mecanismos de reprodução desta desigualdade. Segundo o autor, a Igreja é marcada por um antifeminismo, da qual, faz parte um clero a postos para condenar qualquer tipo de falta feminina, produzindo uma visão pessimista feminina e da feminilidade. Consequentemente, os valores empregados por estas igrejas são familiaristas, quer dizer, patriarcais, impondo uma imagem submissa da mulher, utilizando, a liturgia e textos sagrados como meios de reprodução de uma visão androcêntrica de mundo. A separação entre público (masculino) e privado (feminino) é capaz de esboçar luz sobre a maior participação numérica de mulheres compondo os bancos das igrejas, por serem as mulheres, as incumbidas do espaço doméstico e da reprodução de capital simbólico da família (Boudieu, 2011).

Souza (2004), também esboça hipóteses para a relação mulher/igreja ao buscar,

[...] revelar no processo de produção simbólico-religioso das instituições tradicionais produtoras de sentido, os esforços dessas instituições no sentido de secundarizar a mulher, e no processo de racionalização da atividade religiosa, negar-lhes lugares de poder baseados em discursos sobre a inferioridade natural da mulher. (Souza, 2004, p. 126).

O trecho acima pode ser dividido em dois momentos: em um primeiro momento vê-se o esforço das instituições tradicionais, produtoras de sentidos no processo de produção simbólico-religioso, de secundarizar a mulher. Dentro da tradição católica brasileira pode-se perceber uma clara articulação existente entre a mulher, o plano sobrenatural e sagrado, 
figuras como Maria e Eva, a partir da Idade Média, se tornam "paradigmas antagônicos" (Bellotti, 2007) para a definição da imagem feminina, secundarizada. Resta, portanto, para a mulher o papel de mediadora e ao mesmo tempo pecadora. A imagem feminina não é vista como papel central dentro da religião, mas sim em um papel secundário, no qual quando é "boa" serve como mediação entre o plano humano e o sobrenatural, neste caso entre o fiel e Deus, ou entre fiel e Jesus. Neste caso, a figura feminina assume o papel de Maria, sem pecados. Quando é vista, porém, de uma forma “má", a figura feminina assume a postura de Eva, responsável por comer a maçã e renegar todos ao paraíso.

Em um segundo momento, o trecho anteriormente citado, lança luz sobre o discurso baseado na inferioridade natural da mulher. Ao identificar os sexos/gêneros através da diferenciação biológico-social, na qual vê-se a construção sócio cultural baseada em uma diferenciação a partir do sexo, repercutindo na divisão do trabalho. Divisão de trabalho esta, que se infiltra dentro das Igrejas e gera a disparidade entre homem/mulher frequentadores do grupo de oração, e as responsabilidades que cada sexo tem dentro deste.

O grupo de oração é composto por cinco Ministérios: Acolhida, Música, Intercessão, Cantinho da criança e o de Cura e Libertação. Cada Ministério tem um coordenador responsável por sua administração, que consequentemente responde a um coordenador geral, este responsável pela organização do grupo como um todo, como também, por reger os encontros, tanto os de núcleo quanto os de "Grupão". Cada coordenador é eleito por meio de oração, melhor dizendo, em momentos de oração o Espírito Santo é capaz de revalar para seus servos qual a pessoa mais evoluída espiritualmente e mais bem preparada para assumir aquela função durante os dois próximos anos, tempo que dura uma gestão.

Curiosamente, várias mulheres assumem os cargos de coordenadoras dos Ministérios, porém, quando se trata da coordenação geral do grupo o cargo é assumido por homens, somente uma vez o cargo foi ocupado por uma mulher. De acordo com Bourdieu (2011), as transformações das estruturas das famílias, os acessos das mulheres ao ensino superior e secundário têm colaborado para certa atenuação da dominação masculina, possibilitando o acesso da mulher a cargos públicos, antes impensáveis. No entanto, o autor afirma, que quando se trata de cargos de alta responsabilidade e administração, as mulheres continuam excluídas destes cargos. Indagada sobre a constante eleição de homens para o cargo de coordenador geral, Vera responde: 
No sentido espiritual da coisa, vamos dizer assim, é como se a oração do homem, ela fosse uma oração mais forte, mas não de menosprezo a mulher, não de submissão da mulher, é uma questão mesmo, vamos dizer assim, a mulher é muito sensível, a gente se fragiliza muito facilmente, os homens são mais firmes, no momento da oração e conseguem separar mais o momento de oração e o mundo lá fora. ${ }^{9}$

A fala de Vera demonstra que muitas vezes a mulher não tem consciência que está imersa em uma cultura conservadora e patriarcal legitimada pelas instituições, não percebendo seu papel de submissão diante do homem. A fala demonstra ainda, quão presas estas mulheres estão dentro de uma visão de mundo androcêntrica. Esta não percepção está nítida quando ela diz "não de menosprezo a mulher", percebemos a preocupação que a serva tem em demonstrar que dentro de seu grupo de oração não há desigualdade entre homens e mulheres. Não obstante, quando a serva diz "a gente se fragiliza muito facilmente" é perceptível a imposição biologico-social, impregnada culturalmente na sociedade, a qual, cabe a mulher, o papel de ser frágil, delicada, emotiva. Mulheres que não se enquadrem neste padrão muitas vezes são menosprezadas, e consideradas menos femininas que as demais que assumem estas características. O mesmo se dá quando está mulher tem acesso ao poder, atuando como homens, perdem atributos construídos como obrigatórios pela ordem social da "feminilidade", atuando como mulheres são consideradas como incapacitadas e inaptas à demanda.

De acordo com a serva após o término de cada reunião do "Grupão" o microfone fica a disposição de quem quiser se manifestar em forma de testemunho ou mesmo agradecimento e, apesar da maioria feminina nestes encontros, ela diz, que quando um homem se dispõe a falar,

Muitas vezes os homens que estão lá, e resolvem levantar para dar o testemunho, são testemunhos incríveis, porque é engraçado, os homens são muito duros, são muito firmes no sentido de religião, de não aceitar, de ver até como palhaçada essas coisas assim. E aqueles poucos que se abrem que sentem o que a gente vive lá, são homens que se entregam, igual à mulher tem essa facilidade. ${ }^{10}$

Esta fala de Vera nos leva novamente a dois caminhos: o primeiro mostra como culturalmente o homem deve ser duro, firme, levando novamente a diferenciação biologicosocial, na qual características antagônicas assumem seus papeis. Bourdieu (2011) explica este fato como "Medo viril", o medo que o homem tem de ser excluído do mundo dos homens.

\footnotetext{
${ }^{9}$ Vera, 25 anos, solteira, entrevista realizada em 15 maio 2013.

${ }^{10}$ Vera, 25 anos, solteira, entrevista realizada em 15 maio 2013.
} 
Um segundo caminho, no entanto mostra a difícil conversão masculina a um ethos religioso (Couto, 2002).

Isso confirma mais uma vez os valores, conservadores e patriarcais da sociedade atual, na qual, ao homem, como provedor e inserido a um espaço público, é permitido reger sua própria vida, sem se preocupar em dar satisfação a ninguém. De acordo com Bourdieu (2011), a ordem social simbólica ratifica a dominação masculina sobre a qual é alicerçada em vários sentidos, da divisão social do trabalho, à divisão dos espaços ocupados entre homens e mulheres, passando por características simbólicas, marcadas sempre por antagonismos, tais como: público x privado; seco x úmido; dentro x fora; aberto x fechado. Neste sentido ele é responsável por si e tem esta posição legitimada pela sociedade. A conversão neste ponto, do homem, se faz de uma forma mais difícil, pois este precisa abrir mão deste ethos em que vive e se adequar a um novo, o religioso. No entanto, o assunto neste artigo não é o da conversão, mas, vale ressaltar, que tanto fora quanto dentro da instituição religiosa o ethos é patriarcal e conservador, relegando a mulher a um papel secundário e mais, legitimando este papel através de atos e práticas.

Resta ainda salientar que a visão androcêntrica de mundo se faz presente em todas as instancias da sociedade, inclusive no ato sexual. Na visão de Bourdieu (2011), até mesmo na relação sexual a dominação está embutida, sustentada pela diferenciação entre os órgãos genitais, naturalizando a hierarquia masculina dominante. As vítimas da dominação simbólicas, tidas como, passivas, dóceis, devotas, se tornam objetos simbólicos em um mercado de troca de bens simbólicos. Ao se tornarem objetos de troca, das mulheres têm-se por expectativas que sejam constantemente: femininas, sorridentes, simpáticas. Esta construção de características da identidade "mulher" ganha contornos por estas existirem primeiro para o outro, e pelo outro, neste caso o homem.

Relatos demonstram que na burguesia média norte-americana, estas mulheres chegam ao maior nível de alienação simbólica, se reproduzindo como um exime bem de troca simbólica e reproduzindo de forma magnífica os bens simbólicos de sua família. Neste ponto, a mulher se torna reprodutora de um bem simbólico, produzido pelo marido, e construído e sustentado por agentes e instituições da sociedade. 


\section{A experiência de Vera}

Vera, moradora da cidade de Bicas, solteira, formada em Biologia, atualmente professora da rede estadual, tem vinte e cinco anos e é participante ativa do grupo de oração Mártir São Sebastião da Paróquia São José. A mesma ingressou no grupo através da dor, pois “quem não entra na religião por amor, entra pela dor", palavras de Vera. Segundo ela, sua conversão se deu em um momento bastante difícil em sua vida, um momento de dor por problemas relacionados à sua família, uma doença. Ao entrar para o grupo de oração percebeu uma mudança nítida em sua vida, conseguiu superar seus problemas e passou a enfrentar as dificuldades do cotidiano de uma forma diferente. De acordo com a entrevistada o grupo de oração se tornou uma família, capaz de gerar apoio, de permitir o compartilhamento de problemas, e mais, de fazer surgir uma amizade realmente verdadeira além dos muros do grupo. Sua trajetória dentro do grupo foi de rápida ascensão, desde o primeiro encontro do qual participou no "Grupão" só se passaram três anos. Inicialmente frequentava as reuniões do "Grupão" quando foi convidada para se tornar serva, consequentemente passando a integrar o núcleo do grupo de oração. Desde seu inicio participou de dois Ministérios, o de Música e o de Cura e Libertação, dos quais, faz parte até hoje.

Vera e outro jovem são os únicos abaixo dos trinta que participam do grupo. Indagada sobre essa pequena participação de jovens dentro do grupo, responde que acha que é pela pouca familiaridade do jovem com a Igreja e até mesmo com a dificuldade de seguir as regra dentro da Igreja. Durante uma das entrevistas, contou que cada membro do grupo teve seu motivo particular que acabou resultando na conversão, vale ressaltar que o atual coordenador geral se converteu pelo abuso do álcool, a cura do alcoolismo veio com o tempo. Autoras como (Couto, 2002) demonstram que homens e mulheres se convertem às religiões por motivos distintos, para as mulheres a conversão se faz através de motivos conjugal-familiar, espiritual, ou de saúde, exemplificado acima no testemunho de Vera. Enquanto os homens se convertem por diferentes motivos, tais como: abuso de bebida alcoólica, problemas financeiros, situações de desempregos, entre outros.

Percebemos, portanto, que no interior da igreja católica pesquisada, a utilização de antônimos como base para estrutura sociocultural fundamenta as normas e as condutas dos fieis. Sendo assim, a divisão sexual das coisas e das atividades assume uma postura binária, na qual sempre haverá a oposição entre o masculino e o feminino. Cima/embaixo, frente/atrás, 
duro/mole, seco/molhado são exemplos de antônimos utilizados para conferir conotações e correspondências aos gêneros. A tabela trazida abaixo sintetiza tal pensamento baseado em uma corrente estruturalista acerca do estudo de gênero:

Tabela 1. Oposições binárias conforme o gênero

\begin{tabular}{|l|l|}
\hline Masculino & Feminino \\
\hline Dominante,Cultura, Direito & Dominado, Natureza, Esquerda \\
\hline Seco & Úmido \\
\hline Aberto & Fechado \\
\hline Mente & Corpo \\
\hline Razão & Emoção \\
\hline Público & Privado \\
\hline
\end{tabular}

Criada a partir do livro $A$ dominação masculina, a tabela acima, expressa a maneira pela qual os papeis de gênero são interpretados a partir de um viés estruturalista. Neste esquema, à mulher, biologicamente fềmea, cabe o espaço do privado, da emoção e, ao homem, biologicamente macho, cabe o espaço do público, da razão. Submetido ao masculino, tal qual natureza/cultura, mente/corpo, o feminino necessitaria da oposição ao masculino para ter significação. E a distinção entre sexo/gênero ocorreria da mesma forma, ou seja, a partir de um feminino biológico, haveria que se construir um feminino (gênero) subordinado e em consonância com o sexo. Parece-nos que no grupo de oração a perspectiva de gênero perpetrada ainda se baseia na diferença biologia entre macho e fêmea resultando em posições distintas entre homens e mulheres no interior do espaço religioso.

\section{Considerações finais}

Ao pesquisar o grupo de oração Mártir São Sebastião presente na Paróquia São José, em Bicas, a relação de desigualdade entre gêneros se constata verdadeira, logo, a experiência com o sagrado é vivida e interpretada de modos diferentes entre homens e mulheres. A própria mulher pertencente ao grupo não faz ideia que ajuda a perpetuar e legitimar a desigualdade vivenciada na sociedade e na instituição religiosa, ao dar justificativas para sucessivas eleições masculinas aos cargos responsáveis pela manutenção, organização e administração do grupo. O papel da mulher dentro da igreja, ao longo do tempo, vem sendo transformado, no entanto, a credibilidade dada a ela e a responsabilidade, ainda são 
inferiores as incumbidas aos homens. A maior participação da mulher dentro da Igreja suscita muitas vezes conclusões errôneas e precipitadas acerca da igualdade, pois torna invisíveis as permanências nas posições relativas ocupada pelos sexos. Portanto, o poder é distribuído de maneira desigual entre homens e mulheres dentro da instituição, "naturalizando" o papel de submissão feminino na Igreja, consequentemente, no resto da vida da mulher dentro da sociedade. Não obstante fica o papel de legitimadora da desigualdade entre gêneros perpetuados pela Igreja católica.

\section{Referências Bibliográficas}

BELLOTTI, Karina Kosicki. Gênero e religião. In: Sandra Duarte de Souza (org.). Gênero e religião no Brasil: Ensaios Feministas. São Bernardo do Campo: Editora da Umesp, 2007.

BIRMAN, Patrícia. "Mediação feminina e identidades pentecostais". Cadernos Pagu, n. 6-7, p. 201-226, 1996.

BOURDIEU, Pierre. A dominação masculina. Bertrand Brasil, 2011.

BOURDIEU, Pierre. O Poder simbólico. Bertrand Brasil, 2000.

BUTLER, Judith. Problemas de gênero: feminismo e subversão da identidade. Civilização Brasileira, 2012.

CAMARGO, Cândido Procópio Ferreira. Católicos, Protestantes, Espiritas. Petrópolis: Vozes, 1973.

CARRANZA, Brenda. Catolicismo em movimento. Religião e Sociedade, 2004.

OLIVEIRA, Eliane. A "vida no espírito" e o dom de ser Canção Nova. In: Brenda Carranza, Cecília Mariz, Marcelo Camurça (orgs.). Novas comunidades católicas: em busca do espaço pos-moderno. Aparecida: Ideias \& Letras, 2009.

CARRANZA, Brenda \& MARIZ, Cecília. Novas comunidades católicas: por que crescem. In: Brenda Carranza, Cecília Mariza, Marcelo Camurça (orgs.). Novas comunidades católicas: em busca do espaço pos-moderno. Aparecida: Ideias \& Letras, 2009.

COUTO, Márcia Thereza. Gênero, família e pertencimento religioso na redefinição de thos masculinos e femininos. Anthropologicas, v. 13(1), p. 15-34, 2002.

GEERTZ, Clifford. A interpretação das culturas. Rio de Janeiro: Zahar, 1978.

HERVIEU-LÉGER, Danièle; WILLAIME, Jean-Paul. "Émile Durkein (1858-1917)". In: Sociologia e religião: abordagens clássicas. Aparecida, São Paulo: Ideias \& Letras, 2009.

JURKEWICZ, Regina Soares. Afinal, o que é gênero. Católicas pelo direito de decidir, 1996. 
LOPES, Noêmia de Fátima Siva, et al. Religião, família e gênero entre lideranças comunitárias católicas de Soledade/MG. Revista de Ciências Humanas, v. 11, n. 2, p. 331$343,2011$.

MARIZ, Cecília, Catolicismo no Brasil contemporâneo reavivamento e diversidade. In: Faustino Teixeira \& Renata Manezes (orgs.). As religiões no Brasil: Continuidades e rupturas. Petrópolis: Vozes, 2006.

ROCHA, Maria José. Gênero e religião sob a ótica da redescrição. Revista da abordagem Gestáltica, n. 14(1), p. 102-108, 2008.

SCAVONE, Lucila. Religiões gênero e feminismo. Revista de Estudos da Religião, p. 1-8; 2008 .

SOUZA, Sandra Duarte de. Experiências editoriais feministas. Revista Estudos Feministas, v.12, 2004.

STEIL, Carlos. A igreja dos pobres. Da secularização à mística. In: Maia Green. Religião e Sociedade. Rio de janeiro, 1998.

WEBER, Max. O espírito do capitalismo. In: A ética protestante e o espirito do capitalismo. São Paulo, 1989. 